\title{
The Kabu-ido system: a pioneering solution for uncoordinated groundwater pumping in Japan
}

\author{
T. Endo \\ College of Sustainable System Sciences, Osaka Prefecture University, Sakai city, Osaka Prefecture, Japan \\ Correspondence to: T. Endo (tte23042@osakafu-u.ac.jp)
}

Published: 12 November 2015

\begin{abstract}
The Kabu-ido system was a customary institution for groundwater management in a ring levee area of the Tokai region in Japan. It consists of three programs, a permit system for groundwater pumping, groundwater pricing, and economic compensation. The purpose of this paper is to clarify characteristics of the Kabu-ido as a groundwater management institution.
\end{abstract}

\section{Introduction}

The Kabu-ido system was a customary institution for groundwater management in a ring levee area of the Tokai region in Japan. The ring levees have developed at the confluence of three large rivers, the Ibi, Nagara, and Kiso. Many villages and towns are surrounded by successive levees to prevent against flooding. Such ring levees are often locally called waju in Japanese.

Early in the 19th century, a conflict caused by groundwater pumping took place in the ring levee area. The conflict was mitigated by implementation of three programs, a permit system for groundwater pumping, groundwater pricing, and economic compensation. These programs were gradually developed and later called the Kabu-ido system, which was created in the early 19th century and disappeared around the 1930s. The Kabu-ido system at least existed in the Fukuzuka, Takasu, and Shimogasa ring levees. This study focuses on the Fukuzuka ring levee, which pioneered the Kabu-ido system (Fig. 1).

The Kabu-ido system has been investigated since the 1930s. Bekki (1932), Nakazawa et al. (1936), Katano (1941), Mori (1964), and Matsubara (1968) clarified the Kabu-ido systems in the Takasu and Fukuzuka ring levees based on a wide review on historical documents. These studies were followed by the more recent works of Itoh and Aoki (1987), Kubota (2008), and Shimizu (2014). These works ably clarified the history of the Kabu-ido system, but did not deal with institutional aspects of the system. The purpose of this pa- per is to clarify characteristics of the Kabu-ido system as an institution for groundwater management.

\section{The Kabu-ido system in the Fukuzuka ring levee}

\subsection{Water issues of the Fukuzuka ring levee}

Although the Fukuzuka ring levee is flat, the altitude of its northeast part is higher than that in the southeast. While villages located in higher places are called upper villages, the ones in the lower places are called lower villages. There were ten upper villages and six lower ones within the ring levee. The location and name of those villages are showin in Fig. 2.

Some of the upper villages diverted water from the Ibi River, but began to use groundwater after the advent of pumping techniques in the late 18th century. Accumulated drainage from artesian wells in the upper villages increased flood risk and hindered agricultural activities in the lower villages (Editorial committee of a history of Wanouchi town, 1981).

\subsection{Internal agreement on artesian wells in Fukuzuka ring levee of 1812 (hereafter the 1812 agreement)}

There was a major dispute between the upper and lower villages in 1801. After this trouble, an internal agreement on artesian wells was reached between the upper and lower villages in July 1812 (Internal agreement on artesian wells in Fukuzuka ring levee of 1812; Sakurai, 1934). The agreement includes the following articles. 


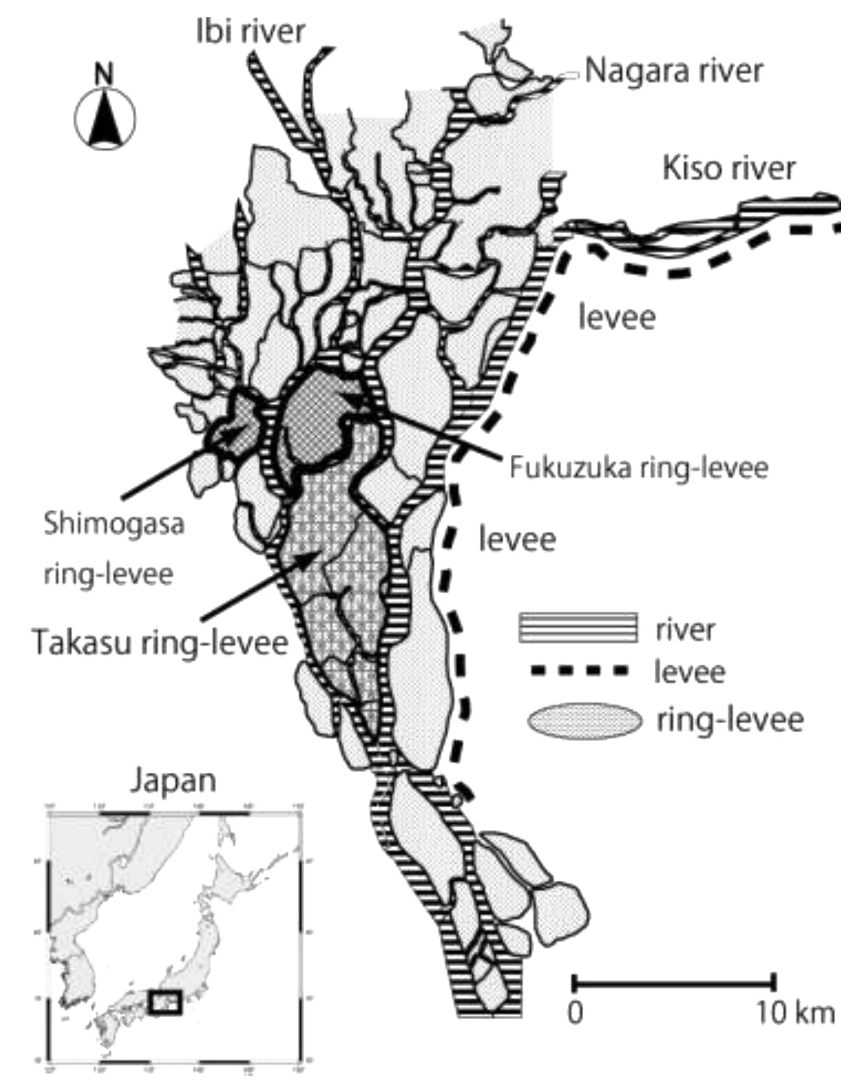

Figure 1. Ring levees around 1870 (based on a map in Nanno town, 1978).

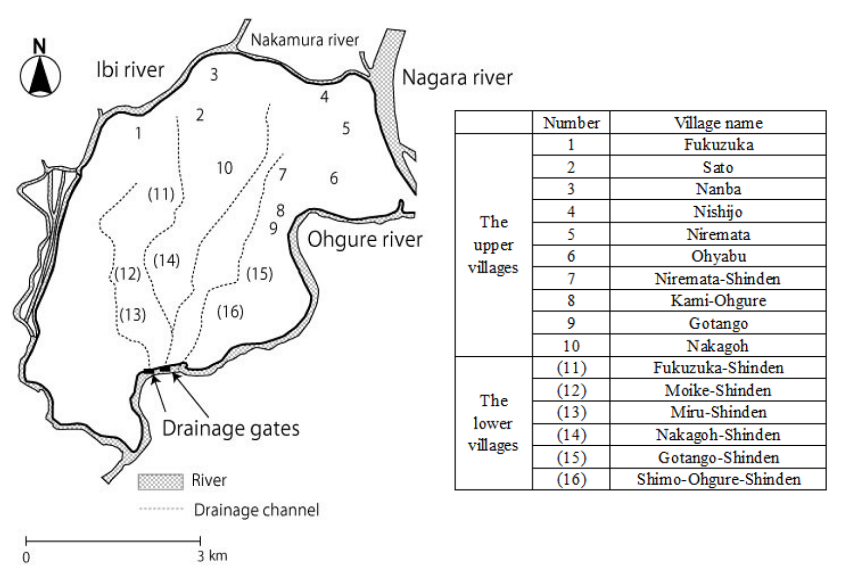

Figure 2. Lower villages are shown by numbers with parentheses. (Based on a map provided by an Editorial committee of a history of Wanouchi town, 1996.)

- Article 1: the number of artesian wells is confined to 45. No additional wells are permitted. If any upper village breaches this article, all existing wells in the village must be eliminated.

- Article 2: four people (two from the upper villages and two from the lower ones) organize well operators. A well must be opened in the presence of these well operators.

- Article 3: the annual salary of a well manager is RYO 1 (a unit of money at the time). The upper villages pay this salary.

- Article 4: each well must be locked. The key is deposited with well managers of the upper villages in a key box. The key of the key box is deposited with well managers of the lower villages.

- Article 5: a broken well must be repaired to prevent unexpected drainage.

- Article 6: those who break the lock to secretly open wells at night must be strictly warned.

- Article 7: a well whose owner intentionally lets groundwater flow under the guise of a broken well should be buried in the presence of well managers from the lower villages.

- Article 8: a well inside a house must be buried.

- Article 9: if an irrigation well does not function adequately, the owner can dig another well in the presence of a well manager from the lower villages.

- Article 10: when drainage gates in the lower villages are closed, wells must not be opened even in case of drought.

- Article 11: if water flows out from a buried well, the well must be completely buried in the presence of the well managers. If residents of the lower villages find that upper village residents secretly use the well without reporting its use, the former residents should consult the local magistrate office.

\subsection{Agreement on artesian wells and changes in drainage channels of 1877 (hereafter the 1877 agreement)}

In 1877, the agreement described above was revised. The new agreement consisted of 19 articles. The articles addressing groundwater management are the following.

- Article 4: the number of wells is set at 395 in the upper villages (including 45 existing wells) and 100 in the lower villages. If additional wells should be necessary, KOKU 7 of rice must be paid per well (rice functioned as currency at the time; the KOKU was a unit of volume). However, a well can be sold and bought with the permission of well managers of the upper and lower villages. After its sale, the well must be completely buried.

- Article 5: well managers consist of two people from the upper villages and two from the lower villages. The annual salary is YEN 5 per person per year. 
- Article 6: numbered certificate poles must be established at all wells. Well managers and assistants must check all wells once per year. Broken wells should be replaced in the presence of well managers. Letting water flow out of a well without a certificate pole is strictly prohibited.

- Article 12: a penalty of $10 \mathrm{koku}$ of rice will be imposed for an uncertified well, and the well must be buried. Half of this fee goes to the person who discovers the uncertified well.

- Article 16: the penalty fee for uncertified wells and revenue from newly permitted wells are used for public works of the ring levee.

- Article 19: a survey of existing (including uncertified) wells must be done and a report submitted no later than 28 February 1878.

In Japanese, $k a b u$ means "the privilege to do business" (Miyamoto, 1977) and ido means "well"; therefore, Kabuido can be interpreted as meaning "privileged well" or "the special right to dig wells". Whereas the word ido is found in the 1812 agreement, the word Kabu-ido is not. Sakurai pointed out that development of the Kabu-ido system was completed in the 1877 agreement because the word had never been used before (Sakurai, 1934).

\section{Characteristics of the Kabu-ido}

\subsection{Correction of negative externality}

The main function of the Kabu-ido was to remedy the negative externality. Groundwater pumping by an actor often causes negative impacts on another actor without any compensation. They include not only drainage problems but also seawater intrusion, decline of groundwater table and land subsidence. These effects are called as "negative externalities". Whatever forms these may take, they suggest excessive use of groundwater (Scitovsky, 1954).

The Kabu-ido system had the function of reducing negative externality. The permit system decreased drainage volume by limiting the total number of wells (Articles 1, 24 and 9 of the 1812 agreement; Article 4 of the 1877 agreement). Groundwater pricing encouraged groundwater users to take negative externality into consideration (Article 4 of the 1877 agreement). This increased the cost of groundwater pumping and promoted internalization. The revenue related to groundwater pricing was used for the construction of drainage gates that further mitigated the negative externality (Article 16 of 1877 agreement).

\subsection{Market-based approach}

The Kabu-ido was a groundwater management institution that used economic tools. Article 4 of the 1877 agreement gave the well manager the ability to permit well transfers. This rule was not found in the 1812 agreement. This transfer rule had a strong relationship with the limitation on total numbers of wells. Given this limitation, those who wanted an additional well had no choice but to buy an existing one from somebody else. Article 4 of the 1877 agreement anticipated the possibility of such a well transaction. In other words, the Kabu-ido introduced a cap-and-trade for wells, which is a type of tradable permit. Cap-and-trade prevents excessive use of resources by introducing a usage limit and promotes their efficient use by permitting transactions.

A document on well transaction includes the phrase "under permission of village mayor and well managers". This shows that a well was transacted under the authorization of well managers as described in the 1877 agreement. This transaction was made on 27 February 1884 and the well price was YEN 15. How widely such a transaction occurred and how well prices changed remain to be proven (Bill of sale on Idokabu, 1884).

\subsection{The Kabu-ido as a self-organized institution}

The Kabu-ido was a self-organized institution that was operated by local groundwater users themselves. The primary issue of self-organized collective action is how to monitor and penalize those who breach local rules without the involvement of external government. It is because voluntary monitoring tends to be hindered by the free-rider problem (Ostrom, 1990). For example, if a lower village conducts such monitoring activities, other villages can enjoy the benefit without contribution. In that situation, no village will have an incentive to monitor and penalize, expecting other villages to do so.

Article 3 of the 1812 agreement solved this problem. The lower villages made upper ones pay the cost of monitoring activities to avoid the free-rider problem. The 1877 agreement also provided other solutions. These were well numbering (Article 6) and a reward system (Article 12). Well numbering not only imposed a cap on the total number of wells but also reduced monitoring cost. It enabled patrolmen from the lower villages to quickly distinguish between an authorized and unauthorized well, because they could easily identify wells without a number and those with an unauthorized duplicate number. In addition, the personal reward system for well detection increased the personal benefit of monitoring activities, towards the voluntary provision of a public good.

\section{Conclusion}

The purpose of this paper was to clarify characteristics of the Kabu-ido as a groundwater management institution.

The first characteristic of the Kabu-ido system is its function. It works to reduce the negative externality related to groundwater pumping. The second characteristic regards economic tools. The 1877 agreement had already introduced 
a cap-and-trade system for groundwater. The final characteristic is that the Kabu-ido was a self-organized institution.

The Kabu-ido was initiated about 200 years ago, but has disappeared. After the 1877 agreement, the government subsidized the installation of electric drainage pumps in the Fukuzuka ring levee. This solved the drainage problem so effectively there was no need for well regulations. In this sense, the Kabu-ido can be regarded as an institution of undeveloped drainage techniques.

Acknowledgements. This work was financially supported by the Asahi Glass Foundation, Societal Adaptation to Climate Change: Integrating Paleoclimatological Data with Historical and Archaeological Evidences (Research Institute for Humanity and Nature Project) and the Japan Society for the Promotion of Science KAKENHI (Grant-in-Aid for Challenging Exploratory Research) grant number 26550101. All historical documents on the Kabu-ido cited (i.e., Agreement on artesian wells and changes in drainage channels of 1877, Bill of sale on Ido-kabu, 1884, and Internal agreement on artesian wells in Fukuzuka ring levee of 1812), are available in the Gifu Prefecture historical document center. The views presented are those of the author and should in no way be attributed to Gifu Prefecture. Responsibility for the text (including any errors) rests entirely with the author.

\section{References}

Agreement on artesian wells and changes in drainage channels, Tanahashi family documents, Gifu Prefecture historical document center, 1877 (in Japanese).

Bekki, A.: A geographical study of ring levees in Seino plain, Collections of essays on geography, 1, 230-282, 1932 (in Japanese).

Bil of Sale on Ido-kabu, Tanahashi family documents, Gifu Prefecture historical document center, 1884 (in Japanese).

Editorial committee of a history of Wanouchi town: A history of Wanouchi town, Dai-ichi Houki Shuppan, Tokyo, 1981 (in Japanse).

Editorial committee of growing Wanouchi: Growing Wanouchi, Wanouchi town, Gifu, 1996 (in Japanse).

Internal agreement on artesian wells in Fukuzuka ring levee, Nakajima family documents, Gifu Prefecture historical document center, 1812 (in Japanese).

Itoh, Y. and Aoki, N.: Ring levee, Gakuseisha, Tokyo, 1987 (in Japanese).

Katano, A.: The Kabu-ido in Fukuzuka and Takasu ring levees, Noubi culture, 1, 47-77, 1941 (in Japanese).

Kubota, M.: Living with rivers: stories of Nagara, Ibi rivers, Fubaisha, 2008.
Matsubara, Y.: On the development of "The Kabu-ido", authorized artesian wells for irrigation in Tkasu-wadju of Nobi Plain, Geographical Review of Japan, 41, 491-504, 1968 (in Japanese).

Miyamoto, M.: A study on Kabu group, Koudansha, Tokyo, 1977 (in Japanese).

Mori, G.: A history of Hirata town, the second volume, Rinsen Book Company, Kyoto, 1964 (in Japanese).

Nakazawa, B., Akiyama, K., and Yamada, K.: A history and geography of ring levee villages, Research Institute of Japanese Agricultural Villages, Tokyo, 1936 (in Japanese).

Nanno town: A history of Nanno town, Nanno town, Gifu, 1978 (in Japanese).

Ostrom, E.: Governing the commons, the evolution of institutions for collective action, Cambridge University Press, New York, 1990.

Sakurai, I.: On the Kabu-ido in Fukuzuka Ring levee, Keiseikaku Documents, Ohgaki City Library, 1934 (in Japanese).

Scitovsky, T.: Two concepts of external economy, J. Polit. Econ., 62, 143-151, 1954.

Shimizu, S.: Fukuzuka ring levee and the Kabu-ido, Wanouchi studies, 3, 2-10, 2014 (in Japanese). 